www.nature.com/ja

\title{
Benzomalvin $\mathrm{E}$, an indoleamine 2,3-dioxygenase inhibitor isolated from Penicillium sp. FN070315
}

\author{
Jun-Pil Jang ${ }^{1,2,8}$, Jae-Hyuk Jang ${ }^{1,3,8}$, Nak-Kyun Soung ${ }^{1,4}$, Hye-Min Kim $^{1,3}$, Sook-Jung Jeong ${ }^{1}$, Yukihiro Asami ${ }^{1,5}$, \\ Kee-Sun Shin ${ }^{6}$, Mee Ree Kim ${ }^{2}$, Hyuncheol $\mathrm{Oh}^{7}$, Bo Yeon Kim ${ }^{1,4}$ and Jong Seog Ahn ${ }^{1,3}$
}

The Journal of Antibiotics (2012) 65, 215-217; doi:10.1038/ja.2011.141; published online 8 February 2012

Keywords: benzodiazepine alkaloid; benzomalvin; indoleamine 2,3-dioxygenase; Penicillium sp.

Indoleamine 2,3-dioxygenase (IDO) is an extrahepatic heme-containing dioxygenase that catalyzes the addition of oxygen across the $\mathrm{C}-2 /$ C-3 bond of indole ring of tryptophan (Trp). ${ }^{1,2}$ This is the initial and rate-limiting step in the catabolism of the essential amino acid Trp to $\mathrm{N}$-formylkynurenine along the kynurenine pathway, the de novo biosynthetic route leading to NAD., ${ }^{3,4}$ T-cell lymphocytes are extremely sensitive to Trp shortage, which cause them to undergo cell cycle arrest in G1, and leads to apoptosis and immunosuppression. ${ }^{5}$ Degradation of Trp by the placenta inhibits T-cell proliferation and, as a result, prevents immunological rejection of tumor or fetus. IDO is expressed ubiquitously but predominately in cells within the immune system, where it is specifically induced in dendritic cells and macrophages at the site of inflammation by cytokines. ${ }^{1}$ It is known that IDO is overexpressed in a variety of diseases, including cancer, ${ }^{6}$ alzheimer's disease, ${ }^{7}$ age-related cataract ${ }^{8}$ and HIV encephalitis. ${ }^{9}$ Recent studies have shown that IDO inhibition might enhance the efficacy of cancer treatment. Indeed result from in vitro and in vivo experiment have suggested an improvement of the efficacy of therapeutic vaccination or chemotherapy by concomitant administration of an IDO inhibitor thus highlighting IDO as an attractive target. ${ }^{6,10-12}$ Although there have been a number of reports on the development of IDO inhibitors, ${ }^{13-16}$ new types of IDO inhibitors having improved pharmacological properties remain to be discovered.

In the course of our screening of the extracts of fungus for IDO inhibitors, we found activity in the culture broth of the soil fungus FN070315. Bioassay-guided fractionation of the extract led us to isolate a new benzodiazepine alkaloid, named benzomalvin E (1), together with two known benzomalvins B (2) and C (3). In this paper, we describe the fermentation, isolation, structure determination and biological activity of benzomalvins. Strain of a fungus, FN070315 was isolated from the soil sample collected from Daejeon in the Korea and was identified on the basis of the ribosomal RNA (rRNA) sequences and morphological evaluation. A GenBank search with the 26S rRNA gene of FN070315 indicated Penicillium jensenii (AY443470), Penicillium canescens (AY484896) as the closest matches, showing sequence identities of $100 \%$ and $99.98 \%$, respectively. Therefore, the fungal strain FN070315 was identified and named as a Penicillium sp. FN070315 (deposited as KCTC1818P at the Korean Collection for Type Culture). Penicillium sp. FN070315 was grown on the PD agar medium for 7 days and was then inoculated into a 500-ml Erlenmeyer flask containing $75 \mathrm{ml}$ of seed culture medium $\mathrm{PD}$ broth $\left(24 \mathrm{gl}^{-1}\right.$ potato dextrose; BD Bioscience, San Jose, CA, USA). Incubation was carried out at $28^{\circ} \mathrm{C}$ for 3 days on a rotary shaker operating at 135 r.p.m. This seed medium $(150 \mathrm{ml})$ was transferred to 81 of the same production medium in a two 14-1 jar fermentor. The fermentation was carried out at $28{ }^{\circ} \mathrm{C}$ for 6 days with agitation at 165 r.p.m. and an air flow of $101 \mathrm{~min}^{-1}$. The culture broth (161) was filtered and extracted three times with an equal volume of EtOAc and the EtOAc layer was concentrated in vacuo. The EtOAc extract $(1.3 \mathrm{~g})$ was subjected to reversed-phase $\mathrm{C}_{18}$ flash column chromatography using a stepwise gradient of $\mathrm{MeOH} / \mathrm{H}_{2} \mathrm{O}$ (from 20/80, 40/60, 60/40, 80/20 to $100 / 0$; $700 \mathrm{ml}$ for each step), to yield five fractions (fractions $1-5)$. The active fraction $3(68.0 \mathrm{mg})$ eluted with $\mathrm{MeOH} / \mathrm{H}_{2} \mathrm{O}(60 / 40)$ was

${ }^{1}$ Chemical Biology Research Center, Korea Research Institute of Bioscience and Biotechnology (KRIBB), Ochang, Korea; ${ }^{2}$ Department of Food and Nutrition, Chungnam National University, Daejeon, Korea; ${ }^{3}$ University of Science and Technology, Daejeon, Korea; ${ }^{4}$ World Class Institute, KRIBB, Ochang, Korea; ${ }^{5}$ Chemical Biology Department, RIKEN Advanced Science Institute, Saitama, Japan; ${ }^{6}$ Biological Resources Center, KRIBB, Daejeon, Korea and ${ }^{7}$ College of Medical and Life Sciences, Silla University, Busan, Korea; 8These authors contributed equally to this work.

Correspondence: Dr JS Ahn, Chemical Biology Research Center, Korea Research Institute of Bioscience and Biotechnology (KRIBB), 30 Yeongudanji-ro, Ochang-eup, Cheongwon-gun, Chungbuk 363-883, Korea.

E-mail: jsahn@kribb.re.kr

or BY Kim, World Class Institute, KRIBB, 30 Yeongudanji-ro, Ochang-eup, Cheongwon-gun, Chungbuk 363-883, Korea.

E-mail: bykim@kribb.re.kr

Received 11 October 2011; revised 6 December 2011; accepted 25 December 2011; published online 8 February 2012 
Table $1{ }^{1} \mathrm{H}$ and ${ }^{13} \mathrm{C}$ NMR data for benzomalvin $\mathrm{E}(1)$ in $\mathrm{CDCl}_{3}$

\begin{tabular}{|c|c|c|c|}
\hline Position & $\delta_{C}$ & $\delta_{H}$ mult $(\mathrm{J}$ in $\mathrm{Hz})$ & $H M B C$ \\
\hline 2 & 165.4 & & \\
\hline 3 & 131.8 & & \\
\hline 4 & 130.9 & $8.04, d(8.1)$ & $2,3,8$ \\
\hline 5 & 129.3 & $7.62, \mathrm{t}(8.1)$ & 3 \\
\hline 6 & 131.1 & $7.72, \mathrm{t}(8.1)$ & 4,8 \\
\hline 7 & 128.5 & $7.61, d(8.1)$ & 8 \\
\hline 8 & 132.8 & & \\
\hline 10 & 161.3 & & \\
\hline 11 & 121.0 & & \\
\hline 12 & 127.3 & $8.23, d(8.1)$ & $10,11,16$ \\
\hline 13 & 127.7 & $7.47, \mathrm{t}(8.1)$ & 11 \\
\hline 14 & 134.8 & $7.70, \mathrm{t}(8.1)$ & 12,16 \\
\hline 15 & 127.5 & $7.51, d(8.1)$ & 11 \\
\hline 16 & 146.2 & & \\
\hline 18 & 152.0 & & \\
\hline 19 & 75.6 & 4.82, d (9.9) & $2,18,20,27$ \\
\hline 20 & 73.1 & $4.15, d(9.9)$ & $19,22,26$ \\
\hline $20-\mathrm{OH}^{\mathrm{a}}$ & & $5.99, d(4.5)$ & $19,20,21$ \\
\hline 21 & 138.7 & & \\
\hline $22 / 26$ & 126.4 & 7.06, br d (7.2) & 21,24 \\
\hline $23 / 25$ & 128.7 & 7.23, brt (7.2) & 21,25 \\
\hline 24 & 129.1 & $7.20, \mathrm{t}(7.2)$ & 26 \\
\hline 27 & 39.0 & $3.48, \mathrm{~s}$ & 2 \\
\hline
\end{tabular}

aspectra were measured in dimethyl sulfoxide (DMSO)-d 6 .

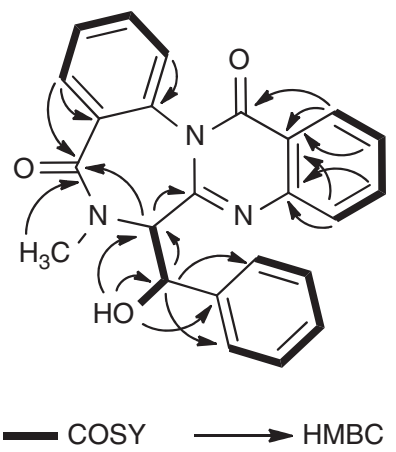

Figure 1 Key 2D NMR correlations of 1 . purified by semi-preparative reverse phase HPLC using an isocratic solvent system of $\mathrm{MeCN} / \mathrm{H}_{2} \mathrm{O}$ (50/50), to yield compound 1 $\left(t_{\mathrm{R}} 16.3 \mathrm{~min}, 3.5 \mathrm{mg}\right), 2\left(t_{\mathrm{R}} 23.5 \mathrm{~min}, 5.5 \mathrm{mg}\right)$ and $3\left(t_{\mathrm{R}} 26.8 \mathrm{~min}\right.$, $5.2 \mathrm{mg}$ ). Compounds 2 and 3 were identified as benzomalvins $\mathrm{B}$ and $\mathrm{C}$ by the comparison of NMR and MS data (Supplementary Figures S8-S11) with those in the literature, respectively. ${ }^{17}$

Compound 1 was assigned the molecular formula $\mathrm{C}_{24} \mathrm{H}_{19} \mathrm{~N}_{3} \mathrm{O}_{3}$ on the basis of HRESIMS data $\left(\mathrm{m} / z 398.1499[\mathrm{M}+\mathrm{H}]^{+}\right.$; calculated for $\mathrm{C}_{24} \mathrm{H}_{20} \mathrm{~N}_{3} \mathrm{O}_{3}, 398.1498$ ) (Supplementary Figure S12) in combination with ${ }^{1} \mathrm{H}$ and ${ }^{13} \mathrm{C}$ NMR data (Table 1). The IR spectrum (Supplementary Figure S13) displayed absorptions due to hydroxyl groups at $3428 \mathrm{~cm}^{-1}$ and carbonyl groups at 1646 and $1697 \mathrm{~cm}^{-1}$. The ${ }^{1} \mathrm{H},{ }^{13} \mathrm{C}$, DEPT and HMQC data (Supplementary Figures S1-S3, S5) of 1 displayed signals assignable to 24 carbons, which were classified into $1 \mathrm{~N}$-methyl carbon at $\delta_{\mathrm{C}} 39.0,2 \mathrm{sp}^{3}$ methine carbons $\left(\delta_{\mathrm{C}} 75.6\right.$ and 73.1), $13 \mathrm{sp}^{2}$ protonated carbons, $6 \mathrm{sp}^{2}$ quaternary carbons and 2 carbonyl carbons $\left(\delta_{\mathrm{C}} 165.4\right.$ and 161.3). Additionally, one exchangeable proton signal was observed in dimethyl sulfoxide (DMSO) $-\mathrm{d}_{6}$, at $\delta$ 5.99 (d, 4.5), and was assigned as hydroxyl proton. The ${ }^{1} \mathrm{H}-{ }^{1} \mathrm{H}$ COSY and HMQC data (Supplementary Figures S4, S5) suggested the presence of one $N$-methyl $\left(\delta_{\mathrm{H} / \mathrm{C}} 3.48 / 39.0\right)$, two sets of 1,2-disubstituted benzenes $\left(\left(\delta_{\mathrm{H} / \mathrm{C}} 8.04 / 130.9,7.72 / 131.1,7.62 / 129.3\right.\right.$ and $7.61 /$ $128.5)$ and $\left(\delta_{\mathrm{H} / \mathrm{C}} 8.23 / 127.3,7.70 / 134.8,7.51 / 127.5\right.$, and $\left.\left.7.47 / 127.7\right)\right)$, one mono-substituted benzene $\left(\delta_{\mathrm{H} / \mathrm{C}} 7.06 / 126.4(\times 2), 7.23 / 128.7\right.$ $(\times 2)$, and $7.20 / 129.1)$, one oxygenated methine $\left(\delta_{\mathrm{H} / \mathrm{C}} 4.15 / 73.1\right)$ and one nitrogenous methine $\left(\delta_{\mathrm{H} / \mathrm{C}} 4.82 / 75.6\right)$. These physicochemical properties and NMR data suggested that 1 was related to benzomalvins. ${ }^{17}$ Interpretation of the $2 \mathrm{D}$ NMR data, including COSY, HMQC, HMBC and NOESY spectra (Supplementary Figures S1-S7), enabled the structure of 1 to be deduced (Figure 1). The HMBC correlation peaks $\left(\mathrm{H}_{3}-27 / \mathrm{C}-2, \mathrm{H}-4 / \mathrm{C}-2, \mathrm{C}-3\right.$ and $\mathrm{C}-8, \mathrm{H}-12 / \mathrm{C}-10, \mathrm{C}-11$ and $\mathrm{C}-16$, H-19/C-2, C-18, C-20 and C-27, H-20/C-19, C-22 and C-26) and the remaining ${ }^{1} \mathrm{H}_{-}{ }^{1} \mathrm{H}$ COSY cross-peak $(\mathrm{H}-19 / \mathrm{H}-20)$, thus, the structure of 1 was determined to be 7-(hydroxy(phenyl)methyl)-6-methyl-6,7dihydrobenzo(6,7)(1,4)diazepino(2,1-b)quinazoline-5,13-dione, as a new benzodiazepine alkaloid, designated as benzomalvin E (1) as shown in Figure 2. Furthermore, the location of a hydroxyl group was confirmed by ${ }^{1} \mathrm{H}-{ }^{1} \mathrm{H}$ COSY and HMBC correlations in DMSO- $\mathrm{d}_{6}$ $\left(\mathrm{COSY}, \mathrm{H}-20\left(\delta_{\mathrm{H}} 3.87\right) / 20-\mathrm{OH}\left(\delta_{\mathrm{H}} 5.99\right) ; \mathrm{HMBC}, 20-\mathrm{OH}\left(\delta_{\mathrm{H}}\right.\right.$ $5.99) / \mathrm{C}-19\left(\delta_{\mathrm{C}} 75.8\right), \mathrm{C}-20\left(\delta_{\mathrm{C}} 71.6\right)$ and C-21 ( $\left.\left.\delta_{\mathrm{C}} 141.4\right)\right)$. The absolute configuration of $\mathrm{C}-20$ was determined by applying the modified Mosher's method. Treatment of 1 with $(S)$ - and (R)-methoxy(trifluoromethyl)phenylacetic acid(MTPA) chloride, yielding the $(R)$ - and $(S)$-MTPA esters (1a and $\mathbf{1 b}$ ), respectively. The difference in chemical shift values $\left(\Delta \delta=\delta_{S}-\delta_{R}\right)$ for the two diastereomeric esters $\mathbf{1 a}$ and $\mathbf{1} \mathbf{b}$ were calculated in order to assign the absolute configurations at C-20 (Figure 3 Supplementary Figures

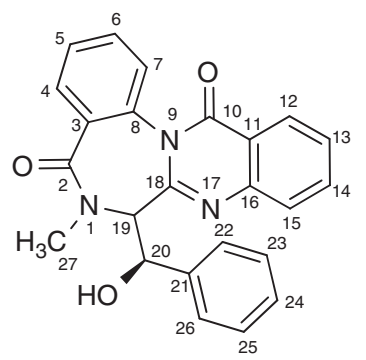

1<smiles>CN1C(=O)c2ccccc2-n2c(nc3ccccc3c2=O)/C1=C\c1ccccc1</smiles>

2<smiles>CN1C(=O)c2ccccc2-n2c(nc3ccccc3c2=O)C12OC2c1ccccc1</smiles>

3

Figure 2 Chemical structures of 1, 2 and $\mathbf{3}$. 
<smiles>CN1C(=O)c2ccccc2-n2c(nc3ccccc3c2=O)C1[C@H](O)c1ccccc1</smiles>

$$
\begin{aligned}
\text { 1a: } \mathrm{R} & =(R) \text {-MTPA ester } \\
\text { 1b: } \mathrm{R} & =(S) \text {-MTPA ester }
\end{aligned}
$$

Figure $3 \Delta \delta$ values $\left(\Delta \delta=\delta_{S}-\delta_{R}\right.$ in ppm) obtained for MTPA esters (1a and $1 \mathrm{~b})$ of 1 .

S14, S15). These data allowed assignment of the absolute configuration of C-20 as $R$ (Figure 3). However, at present, the absolute configuration at C-19 is not determined due to the lack of relevant data. Though 1 was listed in the CAS Registry file (registry No. 1246066-81-8), there are no published data or reports on its stereochemistry.

Compounds 1, 2 and 3 were evaluated for inhibitory activity against IDO. Benzomalvin E (1) showed that the activity of IDO in a dosedependent manner, and its $\mathrm{IC}_{50}$ values were determined as $21.4 \pm 1.2 \mu \mathrm{M}$. A known IDO inhibitor, menadione ( $\left.\mathrm{IC}_{50}=3.7 \pm 0.5 \mu \mathrm{M}\right)$, was employed as a positive control in the assay. On the other hand, compounds $\mathbf{2}$ and $\mathbf{3}$ showed weakly inhibitory activity against IDO with $\mathrm{IC}_{50}$ values of 126 and $130 \mu \mathrm{M}$, respectively.

Benzomalvin derivatives have been reported to function as inhibitor against neuropeptide substance-P at the guinea pig, rat and human neurokinin-1 receptor. ${ }^{17}$ Several IDO inhibitors have been reported to date. ${ }^{18} 1$-Methyltrytophan is the most frequently used inhibitor with a weak $K_{\mathrm{i}}$ of $34 \mu \mathrm{m}$ and is in clinical development at the National Cancer Institute. ${ }^{19,20}$ To our knowledge, the IDO inhibitory activity of the benzomalvin derivatives are now being reported for the first time in this study. Further investigation and optimization of benzomalvins might enable the preparation of new IDO inhibitors potentially useful in the treatment of cancer.

\section{ACKNOWLEDGEMENTS}

This research was supported by grants from the Global R\&D Center and World Class Institute program through the National Research Foundation of Korea (NRF) and 21thC Frontier for Microbial Genomic Application Center funded from the Ministry of Education, Science and Technology of Korea, and a grant from KRIBB Research Initiative Program.
1 Takikawa, O. Biochemical and medical aspects of the indoleamine 2,3-dioxygenaseinitiated L-tryptophan metabolism. Biochem. Biophys. Res. Commun. 338, 12-19 (2005).

2 Munn, D. H. \& Mellor, A. L. Indoleamine 2,3-dioxygenase and tumor-induced tolerance. J. Clin. Invest. 117, 1147-1154 (2007).

3 Rafice, S. A., Chauhan, N., Efimov, I., Basran, J. \& Raven, E. L. Oxidation of L-tryptophan in biology: a comparison between tryptophan 2,3-dioxygenase and indoleamine 2,3-dioxygenase. Biochem. Soc. Trans. 37, 408-412 (2009).

4 Sono, M. Enzyme kinetic and spectroscopic studies of inhibitor and effector interactions with indoleamine 2,3-dioxygenase. 2. Evidence for the existence of another binding site in the enzyme for indole derivative effectors. Biochemistry 28, 5400-5407 (1989).

5 Munn, D. H. et al. Inhibition of T cell proliferation by macrophage tryptophan catabolism. J. Exp. Med. 189, 1363-1372 (1999).

6 Uyttenhove, C. et al. Evidence for a tumoral immune resistance mechanism based on tryptophan degradation by indoleamine 2,3-dioxygenase. Nat. Med. 9, 1269-1274 (2003).

7 Guillemin, G. J., Brew, B. J., Noonan, C. E., Takikawa, O. \& Cullen, K. M. Indoleamine 2,3 dioxygenase and quinolinic acid immunoreactivity in Alzheimer's disease hippocampus. Neuropathol. Appl. Neurobiol. 31, 395-404 (2005).

8 Fujigaki, Y. et al. Immunohistochemical study on caveolin-1alpha in regenerating process of tubular cells in gentamicin-induced acute tubular injury in rats. Virchows Arch. 450, 671-681 (2007).

9 Potula, R. et al. Inhibition of indoleamine 2,3-dioxygenase (IDO) enhances elimination of virus-infected macrophages in an animal model of HIV-1 encephalitis. Blood 106, 2382-2390 (2005).

10 Muller, A. J., DuHadaway, J. B., Donover, P. S., Sutanto-Ward, E. \& Prendergast, G. C. Inhibition of indoleamine 2,3-dioxygenase, an immunoregulatory target of the cancer suppression gene Bin1, potentiates cancer chemotherapy. Nat. Med. 11, 312-329 (2005).

11 Muller, A. J., Malachowski, W. P. \& Prendergast, G. C. Indoleamine 2,3-dioxygenase in cancer: targeting pathological immune tolerance with small-molecule inhibitors. Exp. Opin. Ther. Targets 9, 831-849 (2005).

12 Muller, A. J. \& Prendergast, G. C. Indoleamine 2,3-dioxygenase in immune suppression and cancer. Curr. Cancer Drug Targets 7, 31-40 (2007).

13 Banerjee, T. et al. A key in vivo antitumor mechanism of action of natural product-based brassinins is inhibition of indoleamine 2,3-dioxygenase. Oncogene 27, 2851-2857 (2008).

14 Carr, G., Chung, M. K., Mauk, A. G. \& Andersen, R. J. Synthesis of indoleamine 2,3dioxygenase inhibitory analogues of the sponge alkaloid exiguamine A. J. Med. Chem. 51, 2634-2637 (2008).

15 Macchiarulo, A., Camaioni, E., Nuti, R. \& Pellicciari, R. Highlights at the gate of tryptophan catabolism: a review on the mechanisms of activation and regulation of indoleamine 2,3-dioxygenase (IDO), a novel target in cancer disease. Amino Acids 37, 219-229 (2009).

16 Carr, G. et al. Plectosphaeroic acids A, B, and C, indoleamine 2,3-dioxygenase inhibitors produced in culture by a marine isolate of the fungus Plectosphaerella cucumerina. Org. Lett. 11, 2996-2999 (2009).

17 Sun, H. H., Barrow, C. J., Sedlock, D. M., Gillum, A. M. \& Cooper, R. Benzomalvins, new substance $P$ inhibitors from a Penicillium sp. J. Antibiot. 47, 515-522 (1994).

18 Matsuno, K. et al. S-Benzylisothiourea derivatives as small-molecule inhibitors of indoleamine-2,3-dioxygenase. Bioorg. Med. Chem. Lett. 20, 5126-5129 (2010).

19 Cady, S. G. \& Sono, M. 1-methyl-dl-tryptophan, $\beta$-(3-benzofuranyl)-dl-alanine (the oxygen analog of tryptophan), and $\beta$-[3-benzo(b)thienyl]-dl-alanine (the sulfur analog of tryptophan) are competitive inhibitors for indoleamine 2,3-dioxygenase. Arch. Biochem. Biophys. 291, 326-333 (1991).

20 Muller, A. J. \& Scherle, P. A. Targeting the mechanism of tumoral immune tolerance with small-molecule inhibitors. Nat. Rev. Cancer. 6, 613-625 (2006).

Supplementary Information accompanies the paper on The Journal of Antibiotics website (http://www.nature.com/ja) 